\title{
Recruitment of Lymphocytes during Cutaneous Delayed Hypersensitivity in Nonhuman Primates Is Dependent on E-Selectin and Vascular Cell Adhesion Molecule 1
}

\author{
Alexandra Silber, “ Walter Newman, ${ }^{*}$ Vito G. Sasseville, " Douglas Pauley, ” Dawson Beall, ${ }^{\star}$ Dennis G. Walsh, \\ and Douglas J. Ringler* \\ * Division of Comparative Pathology, Harvard Medical School, New England Regional Primate Research Center, Southborough, \\ Massachusetts 01772; and ${ }^{\ddagger}$ Otsuka America Pharmaceutical, Inc., Rockville, Maryland 20850
}

\section{Abstract}

Previous investigations of cutaneous delayed hypersensitivity (DHR) in humans and animals have demonstrated that lymphocyte recruitment from blood is temporally and spatially associated with the de novo, asynchronous expression of both vascular cell adhesion molecule 1 (VCAM-1) and E-selectin on dermal endothelium. In this study, DHR was induced in rhesus monkeys sensitized against tuberculin in order to investigate the contribution of E-selectin and VCAM-1 in lymphocyte recruitment to skin. Intravenous infusions of neutralizing doses of $F\left(\mathbf{a b}^{\prime}\right)_{2}$ fragments of murine antibodies to either E-selectin or VCAM-1 during the early inductive phases of DHR showed that murine IgG localized to dermal endothelium at the site of DHR in a pattern kinetically similar to the expression of each endothelial adhesion protein. Most importantly, the relative numbers of lymphocytes localized to the inflammatory site were significantly reduced in DHR modified with infusions of antibodies to either VCAM-1 or E-selectin, while the numbers of lymphocytes recruited to skin in the animal given $\mathbf{F}\left(\mathbf{a b}^{\prime}\right)_{2}$ fragments of an irrelevant murine monoclonal antibody of the same isotype and at the same dose were not changed. Moreover, in individual animals, the relative inhibition achieved with a particular antibody was proportional to the magnitude of expression of the targeted adhesion protein. Therefore, both VCAM-1 and E-selectin are functionally relevant in the genesis of cutaneous DHR, and each appears to contribute to lymphocyte recruitment in relation to its relative degree of expression in any one particular animal. (J. Clin. Invest. 1994. 93:15541563.) Key words: rhesus monkeys • skin, endothelium • adhesion $-T$ cell

\section{Introduction}

There is considerable evidence that leukocyte and endothelial adhesion molecules play pivotal roles in the recruitment of leukocytes to sites of inflammatory reactions. Adhesion proteins on endothelium, such as P-selectin, E-selectin, vascular

Dr. Ringler's and Dr. Newman's present address is LeukoSite, Inc., 800 Huntington Avenue, Boston, MA 02115.

Address correspondence to Dr. Ringler.

Received for publication 25 October 1993 and in revised form 22 December 1993.

J. Clin. Invest.

(c) The American Society for Clinical Investigation, Inc. $0021-9738 / 94 / 04 / 1554 / 10 \quad \$ 2.00$

Volume 93, April 1994, 1554-1563 cell adhesion molecule 1 (VCAM-1), ${ }^{1}$ or intercellular adhesion molecule 1 (ICAM-1) are either expressed de novo (VCAM-1, E-selectin), redistributed to the cell membrane from cytoplasmic stores (P-selectin), or upregulated from basal levels (ICAM-1) in multiple organs with various kinds of inflammatory disease activity, including inflammatory bowel disease $(1,2)$, sepsis (3), AIDS encephalitis in monkeys (4), complement-mediated pulmonary injury in rats (5), allograft rejection $(6,7)$, and cutaneous delayed hypersensitivity (DHR) (8-12). In experimental models of inflammatory disease, there are close spatial and temporal associations between the expression of endothelial adhesion molecules and the subsequent localization of leukocytes at the inflammatory site (916). However, because multiple adhesion proteins are usually expressed at inflammatory sites and are likely acting in concert, the relative contribution of specific endothelial adhesion proteins to leukocyte recruitment cannot be assessed using descriptive studies alone.

The use of in vivo-administered murine mAbs to specific leukocyte and endothelial adhesion proteins in various animal models has provided valuable information about the role of specific adhesion proteins in the evolving inflammatory response. When administered to rabbits, $\mathrm{mAbs}$ to the common $\beta$ chain (CD18) of $\beta 2$-integrins on leukocytes significantly reduced PMN recruitment in acute inflammatory models (17$20)$. Similarly, mAbs that inhibit $\beta 2$-integrin interactions with endothelial ICAM-1, when administered to rats, reduced PMN recruitment, vascular permeability, or hemorrhage in various acute inflammatory settings (21-23). Moreover, in the same or similar rat or murine acute inflammatory models, blockades of endothelial E- or P-selectin or leukocyte L-selectin in vivo were found to be efficacious in reducing inflammatory sequelae $(5,24-27)$. Therefore, experimental evidence in animal models suggests that inflammatory disease activity, at least in inflammatory reactions characterized by the presence of PMNs, can be modified by interfering with leukocyte-endothelial adhesive interactions.

In contrast to the work with PMN-mediated inflammatory disease in acute inflammatory models, there is significantly less known about the adhesion molecules utilized for the recruitment of lymphocytes and macrophages in chronic inflammatory settings, primarily because the administration of mAbs for extended periods of time in animal models is usually not clinically feasible or efficacious. Nevertheless, mAbs against the $\beta 1$ -

1. Abbreviations used in this paper: DHR, delayed hypersensitivity; HUVEC, human umbilical vein endothelial cells; ICAM-1, intercellular adhesion molecule 1; RUVEC, rhesus monkey umbilical vein endothelial cells; VCAM-1, vascular cell adhesion molecule 1; VLA-4, very late antigen 4. 
integrin, very late antigen 4 (VLA- $4 ; \alpha 4 \beta 1$-integrin), in rats inhibited lymphocyte recruitment to joints during adjuvant-induced arthritis (28), to central nervous system (CNS) during experimental allergic encephalomyelitis (29), and to skin after injection of proinflammatory cytokines or during DHR (30). In addition, mAbs to ICAM-1 reduced lymphocyte localization in renal allografts and prolonged graft survival in nonhuman primates (6). However, the relative contribution of various endothelial adhesion proteins in an inflammatory reaction characterized by lymphocytic infiltration has not, to our knowledge, been examined.

Recently, using immunohistochemistry, we characterized cutaneous DHR against tuberculin in a nonhuman primate model and found an asynchronous expression of both E-selectin and VCAM-1 on dermal endothelium (9). The contribution of each in lymphocyte recruitment could not be assessed. In this study, we administered relevant neutralizing mAbs to E-selectin and VCAM-1 in vivo during the early inductive phase of DHR in this nonhuman primate model. We found that functional expression of both E-selectin and VCAM-1 is requisite for the genesis of lymphocytic infiltration in cutaneous DHR and that blockade efficacy in any one animal is proportional to the relative degree of expression of the targeted adhesion protein.

\section{Methods}

Animals and antibodies. Cutaneous DHR was induced at several sites on the backs of five healthy adult rhesus monkeys by intradermal administration of $0.1 \mathrm{ml}$ of tuberculin made from standardized filtrates from cultures of Mycobacterium tuberculosis (Coopers Animal Health Inc., Kansas City, KS; lots KC166R and KC167R). These five animals were previously sensitized to $M$. tuberculosis by the intradermal injection of CFA 9-52 mo before the study. Serum and skin injection sites were obtained by venipuncture and surgical biopsy at $0,4,8,24,48,72$, $96,144,168$, and $264 \mathrm{~h}$ after injection. Each injection site was biopsied only once. These animals were maintained in accordance with the guidelines of the Committee on Animals of the Harvard Medical School and those prepared by the Committee on the Care and Use of Laboratory Animals, National Research Council.

Cutaneous DHR was induced in each of the five macaques at least once before administration of mAb therapy in order to compare unmodified DHR with DHR during mAb therapy. For the blockade of E-selectin in vivo, two animals (346-80 and 152-81) were administered $\mathrm{F}\left(\mathrm{ab}^{\prime}\right)_{2}$ fragments of murine mAb 7A9 $(\mathrm{IgG} 1)(31,32)$ intravenously. For the blockade of VCAM-1 in vivo, $F\left(a b^{\prime}\right)_{2}$ fragments of murine mAb $2 \mathrm{G} 7$ ( IgG1 ) $(4,32-34)$ were administered intravenously to two other animals (233-86 and 300-73). $F\left(a^{\prime}\right)_{2}$ fragments were prepared as previously described (32) and were utilized in order to avoid any potential bridging of leukocytes and endothelium via $\mathrm{Fc}$ receptors on the former. Both 7A9 and $2 \mathrm{G} 7 \mathrm{~F}\left(\mathrm{ab}^{\prime}\right)_{2}$ fragments have been previously shown to recognize human E-selectin and VCAM-1, respectively, and maximally inhibit human leukocyte cell binding to IL-1-stimulated human umbilical vein endothelial cells (HUVEC) in vitro at concentrations of $2-10 \mu \mathrm{g} / \mathrm{ml}(31,32)$. In addition, both antibodies recognize the homologous rhesus monkey epitope $(4,9,34,35)$. The dosing regime for each antibody in macaques was determined from pharmacokinetic profiles of single-dose intravenous injections of each antibody $\left(\mathrm{F}\left(\mathrm{ab}^{\prime}\right)_{2}\right.$ fragments $)$ at $2.0 \mathrm{mg} / \mathrm{kg}$ in four additional macaque monkeys. These studies demonstrated that the approximate half-life of 7A9 was $12 \mathrm{~h}$ whereas that of $2 \mathrm{G} 7$ was $5 \mathrm{~h}$ (data not shown). From these data, maintenance of serum neutralizing concentrations of each antibody $(10 \mu \mathrm{g} / \mathrm{ml})$ was projected using an initial loading dose of each antibody of $2.0 \mathrm{mg} / \mathrm{kg}$ intravenously, followed by maintenance doses of $1.0 \mathrm{mg} / \mathrm{kg}$ intravenously every $12 \mathrm{~h}$. mAb infusions were performed during the first $96 \mathrm{~h}$ of DHR. As a control, one animal (animal 55-84) received $\mathrm{F}\left(\mathrm{ab}^{\prime}\right)_{2}$ fragments of $\mathrm{mAb} 5 \mathrm{E} 9(36,37)$ (kindly provided by Drs. Walter Blattler and John Lambert, Immunogen Inc., Cambridge, MA) at the same dosing strategy. mAb 5E9 recognizes the human transferrin receptor (36) yet does not cross-react with the rhesus monkey epitope based on flow cytometry and immunohistochemical techniques (data not shown; Drs. A. Silber and D. Ringler, personal observation).

To determine if desensitization to tuberculin occurred in the study animals upon multiple exposures to intradermal tuberculin, two animals underwent a third DHR after mAb treatment.

Rhesus endothelial cell binding assay. Rhesus monkey umbilical vein endothelial cells (RUVEC) were harvested as previously described (38), and were maintained in M199 medium (Whittaker Bioproducts, Walkersville, MD) containing $20 \%$ endotoxin-tested fetal bovine serum (Gibco Laboratories, Grand Island, NY), $90 \mu \mathrm{g} / \mathrm{ml}$ preservative-free porcine heparin (Sigma Chemical Co., St. Louis, MO), 100 $\mu \mathrm{g} / \mathrm{ml}$ bovine hypothalamus extract (Otsuka America Pharmaceutical Inc., Rockville, MD), $50 \mathrm{U} / \mathrm{ml}$ of penicillin, $50 \mu \mathrm{g} / \mathrm{ml}$ of streptomycin, and $0.25 \mu \mathrm{g} / \mathrm{ml}$ of amphotericin B (Gibco Laboratories). Cells were grown to confluence in gelatin-coated $75-\mathrm{cm}^{2}$ polystyrene flasks and were passaged by dislodgment with washes of $2.5 \mathrm{~g} /$ liter trypsin (Sigma Chemical Co.) and calcium- and magnesium-free Hanks balanced salt solution (HBSS) (Gibco Laboratories) and reseeding onto other gelatin-coated flasks or flat-bottomed 24-well or 96-well plates.

In order to assess the neutralization potential of $7 \mathrm{~A} 9 \mathrm{~F}\left(\mathrm{ab}^{\prime}\right)_{2} \mathrm{mAb}$ to inhibit leukocyte binding to rhesus monkey E-selectin, adhesion of primary ${ }^{51} \mathrm{Cr}$-labeled human neutrophils to resting and cytokine-stimulated RUVEC was evaluated, as previously described using HUVEC (32). Briefly, human neutrophils were obtained from heparinized peripheral blood from which the mononuclear cells had been removed by centrifugation over Ficoll-Hypaque (Sigma Chemical Co.). The neutrophil/red cell pellet was sedimented over $3 \%$ dextran to remove the majority of red cells. Remaining red cells, when necessary, were lysed with hypotonic saline. Purity of neutrophils was $>95 \%$, as determined by Wright-Giemsa staining. RUVEC, at passage 9 or less, were plated onto 24-well plates precoated with gelatin and cultured for $48 \mathrm{~h}$ or until confluent. Some cultures were exposed to $1.0 \mathrm{ng} / \mathrm{ml}$ of human rIL- $1 \beta$ (generous gift of Dr. Y. Hirai, Tokushima Research Institute, Tokushima, Japan) for $4 \mathrm{~h}$ at $37^{\circ} \mathrm{C}$. After rinsing, monolayers were exposed to various concentrations of $\mathrm{F}\left(\mathrm{ab}^{\prime}\right)_{2}$ fragments of $7 \mathrm{~A} 9$ antibody in RPMI 1640 containing $10 \%$ FCS for $30 \mathrm{~min}$ at $37^{\circ} \mathrm{C}$. Control wells contained supplemented medium only or $10 \mu \mathrm{g} / \mathrm{ml}$ of the purified myeloma protein, MOPC-21. All experimental points were done in triplicate. Monolayers were overlaid, in the presence of antibody, with $\sim 10^{6}{ }^{51} \mathrm{Cr}$-labeled neutrophils in a volume of $0.5 \mathrm{ml}$. After $45 \mathrm{~min}$ at $37^{\circ} \mathrm{C}$, monolayers were gently rinsed twice with wash medium at room temperature. The remaining adherent target cells were lysed with 300 $\mu \mathrm{l}$ of $1 \%$ Triton X-100 in PBS. One half of this volume $(150 \mu \mathrm{l})$ was counted in a gamma counter. The amount of ${ }^{51} \mathrm{Cr}$ taken up by $10^{6}$ washed target cells was used to convert data from $\mathrm{cpm} /$ well to number of cells bound/well.

In order to assess the neutralization potential of $2 \mathrm{G} 7 \mathrm{mAb}$ to inhibit leukocyte binding to rhesus monkey VCAM-1, a similar adhesion assay using RUVEC was used, except that adhesion of a human monocytic cell line, THP-1 (ATCC No. TIB 202, Rockville, MD), to resting and TNF- $\alpha$-stimulated RUVEC was assessed, and the method of counting bound cells was modified. Briefly, RUVEC ( $<9$ th passage) were first plated onto gelatin-coated flat-bottomed 96-well plates for $\sim 48 \mathrm{~h}$. Some cultures were subsequently stimulated with $10 \mathrm{ng} / \mathrm{ml}$ human recombinant TNF- $\alpha$ (Sigma Chemical Co.) for $4 \mathrm{~h}$ followed by rinsing in supplemented medium. As described above using 7A9 mAb, RUVEC monolayers were incubated with $F\left(a b^{\prime}\right)_{2}$ fragments of $2 G 7$ $\mathrm{mAb}$ diluted in supplemented RPMI medium for $30 \mathrm{~min}$ at $37^{\circ} \mathrm{C}$. Control wells contained supplemented medium only or $F\left(a b^{\prime}\right)_{2}$ fragments of the irrelevant IgG1 antibody, 5E9. Next, $\sim 0.5 \times 10^{6}$ cells were added to each well and incubated with RUVEC for $30 \mathrm{~min}$ at $37^{\circ} \mathrm{C}$. After incubation, nonadherent cells were removed from wells by 
two consecutive washes with complete medium and placed in another 96-well plate and counted. The number of nonadherent viable cells was determined by a colorimetric assay based on the ability of live cells to reduce a tetrazolium-based compound (MTT) (3-[4,5-dimethylthiazol-2-yl]-2,5-diphenyl tetrazolium bromide) to a blue formazan product (39). Briefly, $0.5 \mathrm{mg} / \mathrm{ml}$ of MTT was added to the nonadherent cell fraction for $4 \mathrm{~h}$ at $37^{\circ} \mathrm{C}$, during which mitochondrial dehydrogenase from the nonadherent cells reduced MTT, resulting in insoluble formazan crystals. The subsequent addition of $150 \mu \mathrm{l} /$ well of anhydrous isopropanol yielded a colorimetric change proportionally related to the quantity of mitochondrial dehydrogenase and resultant formazan crystals. The number of nonadherent cells was then determined from a standard curve of optical density versus cell number, and the number of adherent cells was calculated by subtraction. Consistent results were obtained using RUVEC passaged less than nine times.

Percent inhibition of binding of target cells by both antibodies was calculated as follows: [ (number of bound cells after cytokine minus number of bound cells after $\mathrm{mAb}$ and cytokine)/(number of bound cells after cytokine) $] \times 100$.

Tissues. Skin samples were divided so that half were fixed in $10 \%$ buffered formalin for histology and half embedded in OCT compound (Miles Inc., Elkhart, IN), snap-frozen in 2-methylbutane cooled in dry ice, and stored at $-80^{\circ} \mathrm{C}$ for subsequent immunohistologic techniques. Formalin-fixed skin samples were embedded in paraffin and sections stained with hematoxylin and eosin for routine histologic examination. Immunohistochemistry was performed on desiccated 7.0- $\mu \mathrm{m}$ frozen skin sections mounted on gelatin-coated glass slides. Briefly, tissue sections were fixed in $2 \%$ paraformaldehyde $/ 0.5 \times \mathrm{PBS}(\mathrm{pH} 7.2)$ for 10 $\min$ at $4^{\circ} \mathrm{C}$. To localize and quantify the number of $\mathrm{CD} 2+$ lymphocytes in skin tissue sections, an avidin-biotin-horseradish peroxidase complex technique was utilized, using the mAb, T11/3Pt2H9 (Coulter Immunology, Hialeah, FL) as the primary antibody and diaminobenzidine (Sigma Chemical Co.) as the chromogen, as previously described (40-42). Previous experiments demonstrated that the mAb T11/3Pt2H9 recognizes the rhesus monkey CD2 determinant $(9,40$, 41 ). Immunohistochemistry for E-selectin and VCAM-1 expression in skin was performed using skin sections immunostained using $3 \mathrm{~B} 7$, a murine antibody to human E-selectin, and $2 \mathrm{G} 7$ or $1 \mathrm{E} 7$, murine antibodies to human VCAM-1 $(31,32)$. All three antibodies have been shown previously to recognize the homologous E-selectin or VCAM-1 epitope in rhesus macaques $(4,9,34)$. As negative controls, step sections of each tissue sample were processed under identical conditions with the exception that the primary antibody was substituted with an irrelevant murine antibody of the same isotype and concentration. To localize murine $F\left(a b^{\prime}\right)_{2}$ mAbs in skin tissue sections after in vivo administration, the primary antibody was omitted and a biotinylated goat anti-mouse IgG $\left(\mathrm{F}\left(\mathrm{ab}^{\prime}\right)_{2}\right.$ fragment-specific) (Jackson ImmunoResearch Laboratories, West Grove, PA) was used as the secondary antibody in the sequence. To localize $\mathrm{CD} 2$ for lymphocyte quantification in skin from animals receiving murine $F\left(a b^{\prime}\right)_{2}$ mAbs, whole T11/ $3 \mathrm{Pt} 2 \mathrm{H} 9$ was used as the primary antibody and a biotinylated goat antimouse IgG ( $\mathrm{Fc}$ fragment-specific) (Jackson ImmunoResearch Laboratories) was used as the secondary antibody in the sequence.

Semiquantitative immunohistochemical analysis. The numbers of CD2+ lymphocytes in skin tissue sections were assessed semiquantitatively using a scoring system previously described (9) and modified from that used by Munro et al. $(13,14)$ and Briscoe et al. (15). This scoring method is based on both the extent and composition of leukocyte infiltration as criteria (9). Relative infiltration was judged using hematoxylin and eosin-stained histologic slides and the scores: 0 , normal; 1, small perivascular infiltrates $(<5 \times$ normal size) or increased numbers of scattered leukocytes in the dermis; 2 , small perivascular infiltrates and increased scattered leukocytes in the dermis; 3, large perivascular infiltrates ( $>5 \times$ normal size); or 4 , lichenoid infiltration. Composition of infiltrates was then assessed using immunohistochemistry for $\mathrm{CD} 2$, and assigned scores for the percentage of the infiltrate that was immunoreactive included: 0 , no cells immunoreactive; $1,1-25 \%$; $2,26-50 \% ; 3,51-75 \% ; 4,76-100 \%$. The final score was the product of the values obtained from these two criteria and had a theoretical range from 0 to 16 . Each sample was evaluated blindly by two observers (Drs. Ringler and Silber), and mean scores \pm 1 SEM of animals receiving the same antibody infusions were plotted against time after initiation of DHR and compared to mean scores \pm 1 SEM of the same animals in a previous unmodified DHR. Each animal responded comparably in lymphocyte infiltration scores when examined in multiple subsequent unmodified cutaneous reactions, both before and after antibody treatment.

The kinetic expression of the adhesion molecules VCAM- 1 and E-selectin was characterized semiquantitatively using a similar scoring system as previously described (9). Briefly, endothelial expression of adhesion molecules was evaluated using both numbers of immunoreactive dermal vessels in a $0.5-\mathrm{cm}$ linear biopsy sample and intensity of staining as criteria. For relative numbers of immunoreactive vessels, assigned scores included: 0 , no vessels; $1,1-4$ vessels; $2,5-10$ vessels; 3 , 11-15 vessels; 4, 16-20 vessels; and 5, > 20 vessels. The scores for staining intensity were: 1 , faint; 2 , moderate, with or without 4 vessels being intense; and 3, intense staining of $>4$ dermal vessels. The product of these two values for intensity and numbers of immunoreactive vessels was then used as the final assigned score, which had a theoretical range from 0 to 15 . Each sample was scored without knowledge of the identity of the animal by two of us and means established, as described above.

Quantification of murine IgG in monkey serum. Levels of antibody in serum were determined by a sandwich ELISA. The assay was done by coating Nunc 96-well ELISA plates with $100 \mu$ l of goat anti-mouse $\operatorname{IgG}(\mathrm{H}+\mathrm{L})$ (Jackson ImmunoResearch Laboratories) at $2.5 \mu \mathrm{g} / \mathrm{ml}$ in $0.1 \mathrm{M} \mathrm{Na}$ carbonate buffer, $\mathrm{pH} 9.0$, overnight at $4^{\circ} \mathrm{C}$. Plates were washed with PBS/Tween $0.05 \%$ and blocked for $1 \mathrm{~h}$ at $37^{\circ} \mathrm{C}$ with PBS $/ 1 \%$ bovine serum albumin (Sigma Chemical Co.). The antibody standard for the assay was the same used for the experiment. Standard at $50 \mathrm{ng} / \mathrm{ml}$ in PBS/1\% BSA was added to the first well and serial twofold dilutions in PBS/1\% BSA were done across the plate. Monkey serum samples were initially diluted $1: 25$, and $200 \mu \mathrm{l}$ was added to the plate, with subsequent serial twofold dilutions. Plates were incubated for $2 \mathrm{~h}$ at $25^{\circ} \mathrm{C}$, washed, and $100 \mu \mathrm{l}$ of peroxidase-conjugated goat anti-mouse IgG( $\mathrm{H}+\mathrm{L})$ (Jackson ImmunoResearch Laboratories) at $375 \mathrm{ng} / \mathrm{ml}$ in PBS $/ 1 \%$ BSA added. Plates were incubated an additional $2 \mathrm{~h}$ at $25^{\circ} \mathrm{C}$. Plates were then washed followed by the addition of $O$ phenylenediamine $(1 \mathrm{mg} / \mathrm{ml})$ (Zymed Laboratories, San Francisco, CA) in phosphate citrate buffer and $0.03 \%$ hydrogen peroxide. After shaking for 15 minutes in the dark, the reaction was stopped with the addition of $12.5 \%$ sulfuric acid and read at absorbance $492 \mathrm{~nm}$. Linear regression analysis of the standards was performed and antibody levels calculated. The R-squared value for all assays was at least 0.98 , and triplicate determinations of antibody levels were done on each sample. The limit of detection for the assay was $\sim 150 \mathrm{pg} / \mathrm{ml}$.

Statistics. Significance was determined using the paired Student's $t$ test. Differences between means were considered significant when $P$ $<0.05$.

\section{Results}

mAb cross-Reactivity to rhesus monkey epitopes. Both 7A9 $\mathrm{mAb}$ (anti-E-selectin) and 2G7 (anti-VCAM-1) have been previously shown to recognize homologous rhesus monkey determinants in tissue sections using immunohistochemistry (9) and to inhibit binding of human leukocytes to cytokine-stimulated HUVEC in vitro (32). Furthermore, 2G7 has been shown to inhibit VCAM-1-mediated adhesion of human monocytic cell lines to rhesus monkey endothelium using the Stamper-Woodruff tissue adhesion assay (34). Nevertheless, before infusion into rhesus monkeys, both antibodies were examined for their ability to inhibit adhesion of leukocytes to rhesus monkey E-selectin and VCAM-1, respectively, using 
Table I. Inhibition of Adhesion of Human Neutrophils and THP-1 Cells to Cytokine-stimulated RUVEC

\begin{tabular}{|c|c|c|}
\hline & RUVEC & HUVEC \\
\hline & \multicolumn{2}{|c|}{ percent cells bound } \\
\hline \multicolumn{3}{|l|}{ Granulocytes } \\
\hline IL-1 treatment & 31 & 20 \\
\hline IL-1 and 7A9 mAb & 10 (68\% inhibition) & 9 (55\% inhibition) \\
\hline \multicolumn{3}{|l|}{ THP-1 cells } \\
\hline TNF- $\alpha$ treatment & 52 & NP \\
\hline TNF- $\alpha$ and $2 \mathrm{G} 7 \mathrm{mAb}$ & 34 (36\% inhibition) & NP \\
\hline
\end{tabular}

Data are those from a single representative experiment. RUVEC were stimulated with human rIL-1 $(1.0 \mathrm{ng} / \mathrm{ml})$ or TNF- $\alpha(10 \mathrm{ng} / \mathrm{ml})$ for $4 \mathrm{~h}$ followed by pretreatment with and without $\mathrm{F}\left(\mathrm{ab}^{\prime}\right)_{2} \mathrm{mAbs}$ to E-selectin (7A9) $(10 \mu \mathrm{g} / \mathrm{ml})$ or VCAM-1 $(2 \mathrm{G} 7)(20 \mu \mathrm{g} / \mathrm{ml})$, as described in Methods. Granulocytes were used to evaluate E-selectin-mediated adhesion to RUVEC, while THP-1 cells were used to evaluate VCAM-1-mediated binding. Abbreviation: NP, not performed.

RUVEC. For these experiments, RUVEC were stimulated with either human rIL- 1 or rTNF- $\alpha$, exposed to various concentrations of $F\left(a b^{\prime}\right)_{2}$ fragments of 7A9 or $2 \mathrm{G} 7$, and subsequently examined for changes in adhesive potential for human leukocytes or leukocyte cell lines. As seen in Table I, pretreatment of RUVEC with $F\left(a b^{\prime}\right)_{2}$ fragments of $7 A 9$ inhibited binding of human neutrophils by as much as $68 \%$ compared to no treatment, while pretreatment of RUVEC with $\mathrm{F}\left(\mathrm{ab}^{\prime}\right)_{2}$ fragments of $2 \mathrm{G} 7$ inhibited adhesion of human monocytic cells by $\sim 36 \%$. These values compare favorably to those previously reported for E-selectin-mediated binding of human neutro- phils or VCAM-1-mediated adhesion of mononuclear cells for HUVEC (32). Maximal inhibition was obtained at mAb concentrations from 2 to $10 \mu \mathrm{g} / \mathrm{ml}$ (data not shown), similar to previous observations using HUVEC (32).

$m A b$ infusions. In the two animals receiving infusions of the anti-VCAM-1 mAb, 2G7, pre- and postinfusion ( $5 \mathrm{~min}$ ) concentrations of murine $\mathrm{IgG}$ in serum ranged from 14.2 to 181.1 $\mu \mathrm{g} / \mathrm{ml}$, respectively (Fig. 1). At $120 \mathrm{~h}(5 \mathrm{~d})$ after initiation of DHR and $24 \mathrm{~h}$ after the last infusion of $2 \mathrm{G} 7$, concentrations of murine $\mathrm{IgG}$ in both animals were $<8.0 \mu \mathrm{g} / \mathrm{ml}$. By $144 \mathrm{~h}(6 \mathrm{~d})$ and beyond, serum concentrations of murine IgG in both animals were $<1.0 \mu \mathrm{g} / \mathrm{ml}$. In the two animals receiving 7A9, serum concentrations of murine IgG ranged from 22.2 to 122.4 $\mu \mathrm{g} / \mathrm{ml}$ (Fig. 1). Consistent with the longer half-life of 7A9, by $120 \mathrm{~h}(5 \mathrm{~d})$, both animals still had 7A9 serum concentrations $>15.0 \mu \mathrm{g} / \mathrm{ml}$, levels consistent with an effective E-selectin blockade using RUVEC in vitro. However, by $144 \mathrm{~h} \mathrm{(6} \mathrm{d),}$ animal $346-80 \mathrm{had}<1.0 \mu \mathrm{g} / \mathrm{ml}$ of 7A9 immunoglobulin in serum, while animal 152-81 had a significantly higher (16.6 $\mu \mathrm{g} / \mathrm{ml}$ ) serum concentration of murine IgG. By $168 \mathrm{~h}(7 \mathrm{~d})$, the last time point examined, murine IgG could not be detected in animal 346-80, while animal 152-81 had $\sim 7.3 \mu \mathrm{g} / \mathrm{ml}$ of murine IgG in the serum. Thus, despite a consistently longer half-life for 7A9 antibody in vivo than $2 \mathrm{G} 7$, there was significant variation in 7A9 serum concentrations between study animals.

To determine if infused mAb localized to endothelium at the inflammatory site, immunohistochemical procedures were performed for the localization of $\mathrm{F}\left(\mathrm{ab}^{\prime}\right)_{2}$ murine IgG. As expected, in animals receiving either $7 \mathrm{~A} 9$ or $2 \mathrm{G} 7$, murine $\mathrm{IgG}$ could be detected on superficial and deep dermal venules and rare arterioles within the inflammatory sites (Fig. 2, $C$ and $F$ )

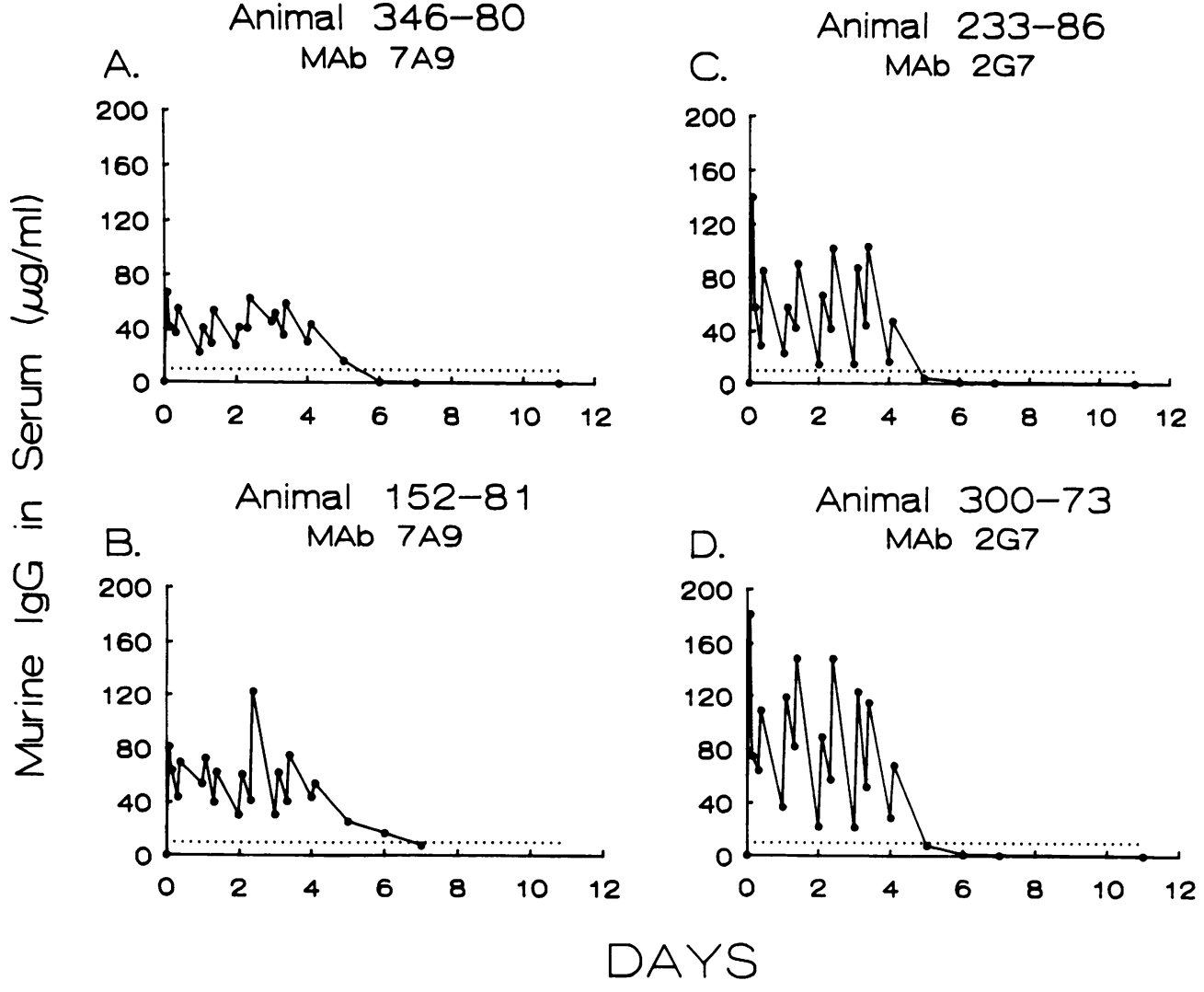

Figure 1. Murine IgG concentrations in serum from the study animals during DHR. ( $A$ and $B$ ) In animals (346-80 and 152-81) receiving anti-E-selectin antibody, 7A9, serum concentrations of IgG were above $10 \mu \mathrm{g} / \mathrm{ml}$ (horizontal dotted line) from initiation of DHR until day 6. ( $C$ and $D$ ) In animals (233-86 and 300-73) receiving anti-VCAM-1 antibodies, serum concentrations of $\mathrm{IgG}$ were above $10 \mu \mathrm{g} / \mathrm{ml}$ from initiation until day 5 . 

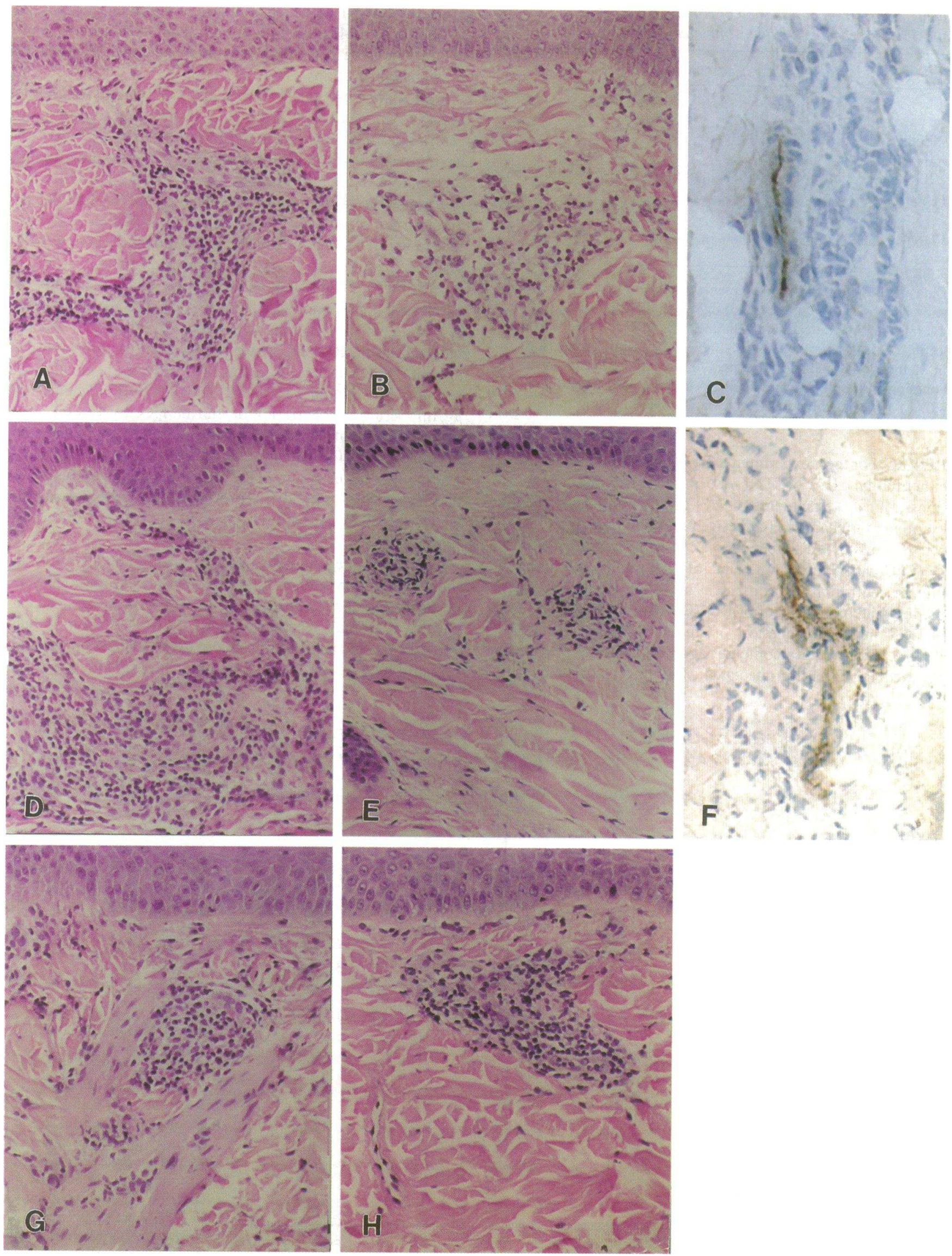

Figure 2. Cutaneous DHR in the rhesus monkey with and without in vivo administration of antibody to endothelial adhesion molecules. $(A-C)$ In animal 233-86, unmodified DHR at day $4(A)$ is characterized by dense angiocentric lymphocytic infiltrates in the superficial dermis. In 
as early as $4 \mathrm{~h}$ after induction of DHR for $7 \mathrm{~A} 9$ and $8 \mathrm{~h}$ for $2 \mathrm{G} 7$, consistent with the kinetic expression of E-selectin and VCAM-1, respectively, in these animals, as reported previously (9). This reactivity persisted in all four animals through day 6 , a time period when the serum concentrations of $\mathrm{mAb}$ in three of the animals were $<1.0 \mu \mathrm{g} / \mathrm{ml}$. However, at day 6 , the staining intensity and number of immunoreactive dermal venules were considerably less than at previous time points. By day 7 , murine IgG could not be localized to any skin sample. Murine IgG could not be localized at any time period in skin samples from the animal receiving the irrelevant $\mathrm{mAb}, 5 \mathrm{E} 9$. Collectively, these data suggest that neutralizing concentrations of $7 A 9$ and $2 \mathrm{G} 7$ were achieved in the serum in all four animals through day 5 of the inflammatory reaction and that these mAbs localized to endothelium at the inflammatory site through day 6.

Clinical efficacy. We next examined if infusions of either anti-E-selectin or anti-VCAM-1 antibodies modified the inflammatory response. Gross examination of the injection sites revealed no appreciable or consistent difference in the size or intensity of erythema at the inflammatory site in untreated DHR versus DHR modified by mAb therapy, either with 7A9 or $2 \mathrm{G} 7$ antibodies. However, on histological examination of skin during the inflammatory course, there was a significant reduction in the number of lymphocytes recruited to the inflammatory site in DHR modified with either anti-E-selectin (7A9) or anti-VCAM-1 (2G7) mAbs, yet the time at which this difference was observed varied for each antibody (Figs. 2 and 3). When compared to a previous unmodified DHR, in the two animals receiving anti-VCAM-1 mAb 2G7, there was a trend for reduced lymphocyte recruitment at $24 \mathrm{~h}$ and beyond; however, this difference was significant only at day 4 $(P<0.01$; Figs. $2, A$ and $B$, and 3$)$. Similarly, in the animals receiving anti-E-selectin $\mathrm{mAb} 7 \mathrm{~A} 9$, there was a diminution of lymphocyte recruitment at most time points examined (Fig. 3 ). However, in contrast to that seen with anti-VCAM-1 immunotherapy, anti-E-selectin mAb infusions statistically reduced local lymphocyte localization at early (day 2 ) and late (days 6 and 7 ) time points in the inflammatory cascade $(P$ $<0.05$; Figs. 2, $D$ and $E$, and 3 ). Furthermore, in both groups of animals receiving $\mathrm{mAbs}$, in addition to a reduction in the size of the perivascular infiltrates, there appeared to be more interstitial edema and a reduction in cellular density within the infiltrates (Fig. $2 B$ ). In the animal receiving irrelevant $\mathrm{mAb}$, there was no apparent difference in the numbers of CD2+ cells at the injection site when compared to DHR in the same animal without mAb infusion (Figs. 2, $G$ and $H$, and 3 ). In subsequent DHR after mAb infusions in two of the study animals, there was no difference in the numbers of $\mathrm{CD} 2+$ lymphocytes at inflammatory sites compared to earlier DHR (data not shown). Therefore, animals did not become desensitized to tuberculin after multiple intradermal exposures.

In an effort to examine the mechanisms associated with outcome from mAb immunotherapy, the relative expression of
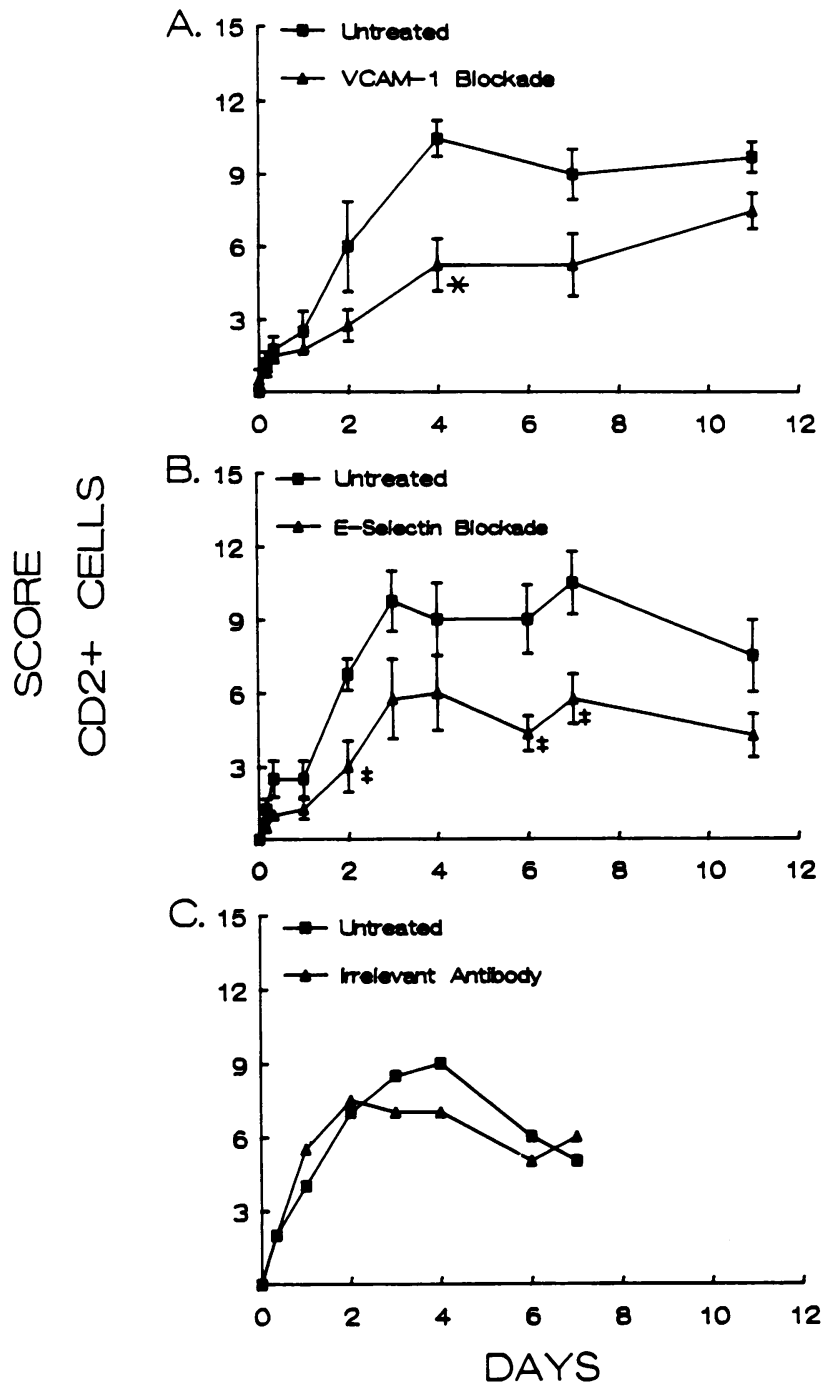

Figure 3. Relative temporal scores (mean \pm 1 SEM) for the numbers of $\mathrm{CD} 2+$ lymphocytes in treated $(-\Delta-)$ and untreated $(-\square-)$ DHR in animals receiving mAbs $2 \mathrm{G} 7$ (anti-VCAM-1) $(A), 7 \mathrm{~A} 9$ (anti-E-selectin) $(B)$, and 5E9 (irrelevant antibody) $(C)$. Significant reductions in the numbers of skin $T$ cells were seen in animals given mAbs to VCAM-1 (day 4; $P<0.01$ ) and E-selectin (days 2, 6, and 7; $P<0.05$ ), yet comparable reductions were not observed in the animal given irrelevant murine antibody. Subscripts at the time points indicate that the values are significantly different from the untreated control group. ${ }^{*} P<0.01,{ }^{\ddagger} P<0.05$.

E-selectin and VCAM-1 was compared to the degree by which $7 A 9$ or $2 \mathrm{G} 7 \mathrm{mAbs}$ were efficacious in a subsequent DHR in reducing lymphocyte localization in a specific animal. VCAM1 expression on dermal endothelium was similar in the two animals receiving $2 \mathrm{G} 7$, and both animals had comparable reductions in the numbers of lymphocytes at the inflammatory site during $\mathrm{mAb}$ administration (Fig. 4). However, in the two

DHR at day 4 modified by in vivo administration of anti-VCAM-1 antibodies $(B)$, lymphocytic infiltrates are edematous, contain fewer lymphocytes, and are typically smaller (not shown). During this VCAM-1 blockade, murine IgG can be localized to dermal venules $(C$, day 3 ). $(D-F)$ In animal 152-81, infusion of antibodies to E-selectin in vivo during DHR $(E)$ resulted in significant reduction in the size of perivascular infiltrates at day 6 compared to unmodified DHR $(D)$. During this E-selectin blockade, murine IgG can be localized to dermal venules $(F$, day 2). ( $G$ and $H$ ) In contrast, irrelevant murine antibodies given to animal 55-84 $(H)$ did not change the character of lymphocytic infiltration during DHR at day 3 compared to DHR without mAb administration $(G) .(A, B, D, E, G$, and $H) \times 180$, hematoxylin and eosin; $(C$ and $F) \times 360$, immunoperoxidase technique with Mayer's hematoxylin counterstain). 

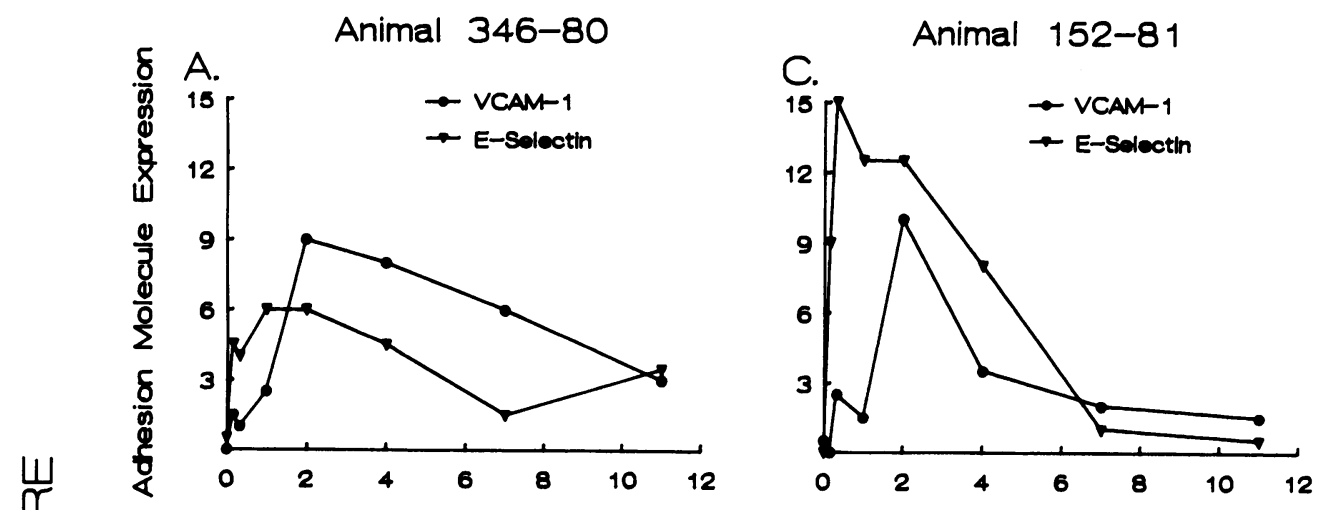

Figure 4. Individual scores for E-selectin $(-\nabla-)$ and VCAM-1 (- - - expression in untreated DHR in animals $346-80$ and $152-81$ $(A$ and $C$ ) and relative scores for the numbers of $\mathrm{CD} 2+$ lymphocytes with (- and without (- - infusions of $\mathrm{mAb}$ to E-selectin in the same animals $(B$ and $D)$. While both animals had comparable levels of VCAM1 immunoreactivity in untreated DHR ( $A$ and $C$ ), animal 152-81 had approximately twice the score for E-selectin expression during the first $2 \mathrm{~d}$ than did animal 346-80 ( $A$ and $C$ ). When antibodies to E-selectin were
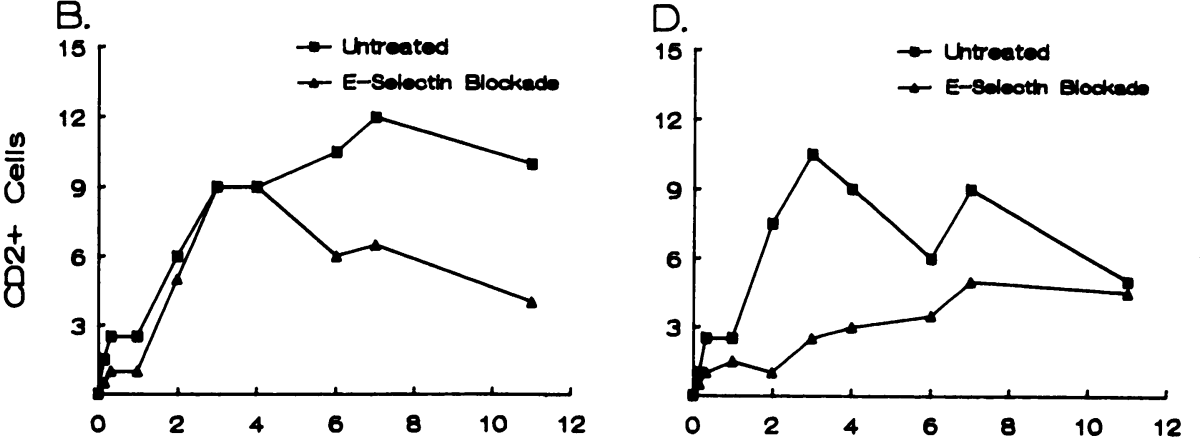
administered ( $B$ and $D$ ), a significant diminution of the numbers of skin $\mathrm{CD} 2+\mathrm{T}$ cells was observed in animal 152-81 at all time points examined, with the most noticeable reductions seen at days 2-4 $(D)$. In contrast, comparable reductions in the numbers of skin $\mathrm{CD} 2+\mathrm{T}$ cells at days 2-4 were not observed in animal $346-80$ during DHR modified with infusions of antibodies to Eselectin $(B)$.

animals receiving anti-E-selectin $\mathrm{mAb}, 7 \mathrm{~A} 9$, there were dramatic differences in E-selectin expression on dermal endothelium (Fig. 4). In the animal (152-81) with the highest E-selectin expression, 7A9 mAb infusions were associated with the largest reduction in the number of cutaneous lymphocytes, predominantly from $8 \mathrm{~h}$ up to 11 days after DHR induction (Fig. 4 ). In contrast, in the other animal (346-80) receiving 7A9 $\mathrm{mAb}$, E-selectin expression was approximately half that seen in animal 152-81, and attenuation in the numbers of lymphocytes recruited at the site was not seen until day 6 and beyond (Fig. 4). Therefore, the outcome derived from an in vivo E-selectin blockade in DHR, at least in terms of lymphocyte recruitment, was associated with the relative extent of E-selectin expression on dermal endothelium.

\section{Discussion}

Because we and others have previously demonstrated that cutaneous DHR is characterized by the dual, asynchronous, de novo expression of E-selectin and VCAM-1 $(8-10,12,43)$, the purpose of this study was to examine the contribution of each endothelial adhesion protein in the genesis of clinically apparent cutaneous DHR by infusing neutralizing doses of murine $\mathrm{mAbs}$ to each protein in a relevant animal model. We demonstrate that: $(a)$ blocking mAbs to either E-selectin or VCAM-1, when administered to rhesus monkeys, localize to endothelium at sites of cutaneous DHR; $(b)$ localization of both mAbs at cutaneous sites is spatially and temporally similar to the ex- pression of E-selectin and VCAM-1; $(c)$ localization of either $\mathrm{mAb}$ at the inflammatory site is associated with a significant reduction in the numbers of dermal lymphocytes within angiocentric infiltrates; and $(d)$ the relative inhibition of lymphocyte recruitment is associated with the magnitude of expression of the targeted adhesion molecule.

It has been previously shown that specific endothelial adhesion proteins and their respective leukocyte ligands can mediate adhesion of leukocytes in vitro $(31,32,44-54)$ and that these endothelial adhesion proteins are expressed at inflammatory sites (1-7, 9-12). Although it has been hypothesized from these data that endothelial and leukocyte adhesion molecules play a fundamental role in leukocyte recruitment and subsequent tissue injury at an inflammatory site, only recently, using neutralizing mAbs and animal models of inflammatory disease, has this role been documented. mAbs to integrins (either CD18, CD1 1a, or CD1 1b) or selectins, when administered to either rodents or rabbits during an acute inflammatory response, reduced PMN recruitment to the inflammatory site $(17-20,26,27)$ and often attenuated endothelial injury, as assessed by hemorrhage and / or edema $(5,21-23,25)$. Because adhesion of PMNs to endothelium can result in significant PMN-mediated endothelial injury (55), it follows that inhibition of adhesion of PMNs to endothelium at inflammatory sites can have clinically beneficial effects. Significantly less experimental work has focused on mononuclear leukocyte adhesion in chronic inflammatory disease, yet administration of mAbs against the $\beta 1$ integrin, VLA- 4 ( $\alpha 4 \beta 1$-integrin), in rats 
inhibited lymphocyte recruitment in a number of inflammatory settings (28-30), and mAbs to ICAM-1 given to nonhuman primates reduced lymphocytic infiltration in renal allografts and prolonged graft survival (6). With regard to the role of VCAM-1 /VLA-4 interactions in lymphocyte recruitment at an inflammatory site, our data contribute to the findings described in rats for EAE (29), adjuvant-induced arthritis (28), and cutaneous inflammation (30). Moreover, our data extend these observations by demonstrating, for the first time, that inhibition of lymphocytic recruitment in vivo can be accomplished by $\mathrm{mAb}$ therapy directed against either endothelial Eselectin or VCAM-1.

In our study using nonhuman primates, blockades directed against E-selectin or VCAM-1 did not appear to ameliorate the vascular permeability associated with the inflammatory response, as significant perivascular dermal edema could be visualized histologically in samples from animals receiving mAbs to either endothelial protein. Although increased vascular permeability may theoretically arise from endothelial injury secondary to murine antibody localization on the membrane, there are a number of reasons that argue against this notion. First, this edema is not likely secondary to endothelial injury mediated by antibody-dependent cell-mediated cytotoxicity mechanisms in that $\mathrm{F}\left(\mathrm{ab}^{\prime}\right)_{2}$ fragments of murine antibodies were used for all in vivo infusions. Secondly, in other animal studies using murine antibodies to E-selectin, similar observations were not described $(25,56,57)$. Thirdly, we cannot be certain that increased vascular permeability occurred in animals treated with murine antibodies since precise kinetic and quantitative assessments of vascular leakage were not performed. It is possible that the relative degree of vascular permeability was similar in both unmodified DHR and DHR modified with mAb therapy, and edema was histologically more obvious in a context of less lymphocytic infiltration during mAb therapy. In fact, because our scoring system used the relative size of angiocentric dermal infiltrates as criterion, regardless of edema or cellular density of these infiltrates, it is possible that in animals given mAbs, the degree of inhibition of lymphocytic recruitment was underestimated. Further evaluations using computer-assisted image analysis and precise kinetic quantification of lymphocyte numbers in tissues, as well as analysis of vascular permeability from postcapillary venules, will be needed to address this issue.

With regard to the relative contribution of E-selectin versus VCAM-1 in lymphocyte recruitment in cutaneous DHR, the results of this study indicate that both proteins play significant roles, yet apparently at different periods during the evolution of the cascade. A statistically significant reduction in lymphocyte localization in skin was observed at days 2,6 , and 7 when $\mathrm{mAb}$ to E-selectin was administered. In contrast, when mAb to VCAM-1 was administered during DHR, a significant reduction in the number of lymphocytes was observed only at day 4 . However, we cannot exclude that if more animals were examined, the statistical benefit recognized from administration of mAbs to either E-selectin, VCAM-1, or both in nonhuman primates would modify this putative temporal relationship. Nor can it be entirely excluded that antibody therapy indirectly inhibited lymphocyte recruitment by mechanisms independent from E-selectin- and VCAM-1-mediated lymphocyte endothelial adhesion. Although unlikely given the lack of inhibition seen in the animal given a similarly-prepared irrelevant antibody, further studies will be needed to address potential indirect influences of antibody administrations, such as alterations in numbers and activation of peripheral blood lymphocytes, monocyte trafficking to the inflammatory site, and systemic cytokine elaboration, on lymphocyte recruitment during cutaneous DHR or other inflammatory reactions.

The results from this study underscore the need to evaluate, on a case-by-case basis, the extent of adhesion molecule expression at inflammatory sites during experimental therapeutic trials aimed at the functional blockade of a specific adhesion molecule. Although only examined in four animals, the reduction in the numbers of lymphocytes at the inflammatory site with mAb therapy paralleled the extent of expression of the specific endothelial adhesion protein in prior DHR. Both animals receiving mAb against VCAM-1 had similar patterns of VCAM-1 expression on dermal endothelium, and both had comparable inhibition of the numbers of lymphocytes at the inflammatory site. In contrast, in the two animals receiving $\mathrm{mAb}$ against E-selectin, one animal had approximately twice the score for E-selectin expression than the other in DHR trials before mAb infusions, yet in the same DHR, both animals had similar numbers of lymphocytes recruited to skin. Interestingly, it was the animal with more E-selectin expression that demonstrated the greatest attenuation of lymphocyte localization at injection sites during subsequent infusions of $\mathrm{mAb}$ against E-selectin. Similarly, other factors that may influence outcome during blockades of E-selectin and VCAM-1 in vivo include variations in soluble concentrations of either protein in serum and the resultant effect on $\mathrm{mAb}$ bioavailability and concentrations of leukocyte chemoattractants at the inflammatory site. Clearly, further examination of the extent of expression of chemokines and endothelial adhesion proteins, both locally at the site and in soluble form in serum, is required to document if measurement of these mediators would be useful in determining the appropriateness of specific immunotherapy in chronic inflammatory disease.

In conclusion, our results demonstrate, for the first time, that lymphocyte recruitment in cutaneous DHR can be inhibited by the neutralization of either endothelial E-selectin or VCAM-1. Furthermore, although intuitive, our results suggest that the clinical success associated with the blockade of a specific endothelial adhesion molecule may be directly associated with the extent of expression of that endothelial adhesion molecule. Further work is required to investigate which lymphocyte subsets are most affected by E-selectin or VCAM-1 blockades, the clinical utility of simultaneous mAb therapy against both endothelial adhesion proteins, and the effect of murine mAbs directed against endothelial determinants on vascular integrity and permeability.

\section{Acknowledgments}

The authors thank Dr. Prahbat Sehgal and Lorraine Lynch for surgical assistance, Beverly Blake for editorial assistance, and Edie Estabrook for manuscript preparation.

This work was supported by awards AI25644, AI29855, and RROO168 from the National Institutes of Health.

\section{References}

1. Koizumi, M., N. King, R. Lobb, C. Benjamin, and D. K. Podolsky. 1992. Expression of vascular adhesion molecules in inflammatory bowel disease. Gastroenterology. 103:840-847. 
2. Malizia, G., A. Calabrese, M. Cottone, M. Raimondo, L. K. Trejdosiewicz, C. J. Smart, L. Oliva, and L. Pagliaro. 1991. Expression of leukocyte adhesion molecules by mucosal mononuclear phagocytes in inflammatory bowel disease. Gastroenterology. 100:150-159.

3. Drake, T. A., J. Cheng, A. Chang, and F. B. Taylor, Jr. 1993. Expression of tissue factor, thrombomodulin, and E-selectin in baboons with lethal Escherichia coli sepsis. Am. J. Pathol. 142:1458-1470.

4. Sasseville, V. G., W. A. Newman, A. A. Lackner, M. O. Smith, N. C. G. Lausen, D. Beall, and D. J. Ringler. 1992. Elevated vascular cell adhesion molecule-1 in AIDS encephalitis induced by simian immunodeficiency virus. $\mathrm{Am}$. J. Pathol. 141:1021-1030.

5. Mulligan, M. S., M. J. Polley, R. J. Bayer, M. F. Nunn, J. C. Paulson, and P. A. Ward. 1992. Neutrophil-dependent acute lung injury: requirement for P-selectin (GMP-140). J. Clin. Invest. 90:1600-1607.

6. Cosimi, A. B., D. Conti, F. L. Delmonico, F. I. Preffer, S-L. Wee, R. Rothlein, R. Faanes, and R. B. Colvin. 1990. In vivo effects of monoclonal antibody to ICAM-1 (CD54) in nonhuman primates with renal allografts. J. Immunol. $144: 4604-4612$

7. Briscoe, D. M., F. J. Schoen, G. E. Rice, M. P. Bevilacqua, P. Ganz, and J. S. Pober. 1991. Induced expression of endothelial-leukocyte adhesion molecules in human cardiac allografts. Transplantation. 51:537-547.

8. Mackay, C. R., W. Marston, and L. Dudler. 1992. Altered patterns of T cell migration through lymph nodes and skin following antigen challenge. Eur. $J$. Immunol. 22:2205-2210.

9. Silber, A., W. Newman, K. A. Reimann, E. Hendricks, D. Walsh, and D. J. Ringler. 1994. Kinetic expression of endothelial adhesion molecules and relationship to leukocyte recruitment in two cutaneous models of inflammation. Lab. Invest. In press.

10. Norris, P., R. N. Poston, D. S. Thomas, M. Thornhill, J. Hawk, and D. O. Haskard. 1991. The expression of endothelial leukocyte adhesion molecule-1 (ELAM-1), intercellular adhesion molecule-1 (ICAM-1), and vascular cell adhesion molecule-1 (VCAM-1) in experimental cutaneous inflammation: a comparison of ultraviolet B erythema and delayed hypersensitivity. J. Invest. Dermatol. 96:763-770.

11. Brasch, J., and W. Sterry. 1992. Expression of adhesion molecules in early allergic patch test reactions. Dermatology. (Basel). 185:12-17.

12. Waldorf, H. A., L. J. Walsh, N. M. Schechter, and G. F. Murphy. 1991. Early cellular events in evolving cutaneous delayed hypersensitivity in humans. Am. J. Pathol. 138:477-486.

13. Munro, J. M., J. S. Pober, and R. S. Cotran. 1991. Recruitment of neutrophils in the local endotoxin response: association with de novo endothelial expression of endothelial leukocyte adhesion molecule-1. Lab. Invest. 64:295-299.

14. Munro, J. M., J. S. Pober, and R. S. Cotran. 1989. Tumor necrosis factor and interferon-gamma induce distinct patterns of endothelial activation and associated leukocyte accumulation in skin of Papio anubis. Am. J. Pathol. 135:121133.

15. Briscoe, D. M., R. S. Cotran, and J. S. Pober. 1992. Effects of tumor necrosis factor, lipopolysaccharide, and IL-4 on the expression of vascular cell adhesion molecule-1 in vivo: correlation with $\mathrm{CD}^{+} \mathrm{T}$ cell infiltration. $\mathrm{J}$. Immunol. 149:2954-2960.

16. Lewis, R. E., M. Buchsbaum, D. Whitaker, and G. F. Murphy. 1989. Intercellular adhesion molecule expression in the evolving human cutaneous delayed hypersensitivity reaction. J. Invest. Dermatol. 93:672-677.

17. Price, T. H., P. G. Beatty, and S. R. Corpuz. 1987. In vivo inhibition of neutrophil function in the rabbit using monoclonal antibody to CD18. J. Immunol. 139:4174-4177.

18. Arfors, K.-E., C. Lundberg, L. Lindbom, K. Lundberg, P. G. Beatty, and J. M. Harlan. 1987. A monoclonal antibody to the membrane glycoprotein complex CD18 inhibits polymorphonuclear leukocyte accumulation and plasma leakpine in vivo. Blood. 69:338-340.

19. Doerschuk, C. M., R. K. Winn, H. O. Coxson, and J. M. Harlan. 1990. CD18-dependent and -independent mechanisms of neutrophil emigration in the pulmonary and systemic microcirculation of rabbits. J. Immunol. 144:23272333.

20. Barton, R. W., R. Rothlein, J. Ksiazek, and C. Kennedy. 1989. The effect of anti-intercellular adhesion molecule-1 on phorbol-ester-induced rabbit lung inflammation. J. Immunol. 143:1278-1282.

21. Mulligan, M. S., C. W. Smith, D. C. Anderson, R. F. Todd, III, M. Miyasaka, T. Tamatani, T. B. Issekutz, and P. A. Ward. 1993. Role of leukocyte adhesion molecules in complement-induced lung injury. J. Immunol. 150:24012406.

22. Mulligan, M. S., J. Varani, J. S. Warren, G. O. Till, C. W. Smith, D. C. Anderson, R. F. Todd III, and P. A. Ward. 1992. Roles of $\beta_{2}$ integrins of rat neutrophils in complement- and oxygen radical-mediated acute inflammatory injury. J. Immunol. 148:1847-1857.

23. Mulligan, M. S., K. J. Johnson, R. F. Todd, III, T. B. Issekutz, M. Miyasaka, T. Tamatani, C. W. Smith, D. C. Anderson, and P. A. Ward. 1993. Requirements for leukocyte adhesion molecules in nephrotoxic nephritis. J. Clin. Invest. 91:577-587.

24. Mulligan, M. S., J. C. Paulson, S. D. Frees, Z-L. Zheng, J. B. Lowe, and
P. A. Ward. 1993. Protective effects of oligosaccharides in P-selectin-dependent lung injury. Nature (Lond.). 364:149-151.

25. Mulligan, M. S., J. Varani, M. K. Dame, C. L. Lane, C. W. Smith, D. C. Anderson, and P. A. Ward. 1991. Role of endothelial-leukocyte adhesion molecule 1 (ELAM-1) in neutrophil-mediated lung injury in rats. J. Clin. Invest. 88:1396-1406.

26. Jutila, M. A., L. Rott, E. L. Berg, and E. C. Butcher. 1989. Function and regulation of the neutrophil MEL-14 antigen in vivo: comparison with LFA-1 and Mac-1. J. Immunol. 143:3318-3324.

27. Watson, S. R., C. Fennie, and L. A. Lasky. 1991. Neutrophil influx into an inflammatory site inhibited by a soluble homing receptor-IgG chimaera. Nature (Lond.). 349:164-167.

28. Issekutz, T. B. and A. C. Issekutz. 1991. T lymphocyte migration to arthritic joints and dermal inflammation in the rat: differing migration pattern and the involvement of VLA-4. Clin. Immunol. Immunopathol. 61:436-447.

29. Yednock, T. A., C. Cannon, L. C. Fritz, F. Sanchez-Madrid, L. Steinman, and N. Karin. 1992. Prevention of experimental autoimmune encephalomyelitis by antibodies against $\alpha 4 \beta 1$ integrin. Nature (Lond.). 356:63-66.

30. Issekutz, T. B. 1991. Inhibition of in vivo lymphocyte migration to inflammation and homing to lymphoid tissues by the TA-2 monoclonal antibody: a likely role for VLA-4 in vivo. J. Immunol. 147:4178-4184.

31. Shimizu, Y., S. Shaw, N. Graber, T. V. Gopal, K. J. Horgan, G. A. van Seventer, and W. Newman. 1991. Activation-independent binding of human memory T cells to adhesion molecule ELAM-1. Nature (Lond.). 349:799-802.

32. Graber, N., T. V. Gopal, D. Wilson, L. D. Beall, T. Polte, and W. Newman. 1990. T cells bind to cytokine-activated endothelial cells via a novel, inducible sialoglycoprotein and endothelial leukocyte adhesion molecule-1. J. Immunol. 145:819-830.

33. Polte, T., W. Newman, G. Raghunathan, and T. V. Gopal. 1991. Structural and functional studies of full-length vascular cell adhesion molecule-1: internal duplication and homology to several adhesion proteins. DNA Cell Biol. 10:349-357.

34. Sasseville, V. G., W. A. Newman, S. J. Brodie, P. Hesterberg, D. Pauley, and D. J. Ringler. 1994. Monocyte adhesion to endothelium in SIV-induced AIDS encephalitis is mediated by VCAM-1/ $\alpha 4 \beta 1$ integrin interactions. Am. J. Pathol. 144:27-40.

35. Horvath, C. J., R. D. Hunt, M. A. Simon, P. K. Sehgal, and D. J. Ringler. 1993. An immunohistologic study of granulomatous inflammation in SIV-infected rhesus monkeys. J. Leukocyte Biol. 53:532-540.

36. Scott, C. F., Jr., V. S. Goldmacher, J. M. Lambert, J. V. Jackson, and G. D. McIntyre. 1987. An immunotoxin composed of a monoclonal antitransferrin receptor antibody linked by a disulfide bond to the ribosome-inactivating protein gelonin: potent in vitro and in vivo effects against human tumors. J. Natl. Cancer Inst. 79:1163-1172.

37. Todd, R. F. III, and S. F. Schlossman. 1982. Analysis of antigenic determinants on human monocytes and macrophages. Blood. 59:775-786.

38. Jaffe, E. A., R. L. Nachman, C. G. Becker, and C. R. Minick. 1973. Culture of human endothelial cells derived from umbilical veins: indentification by morphologic and immunologic criteria. J. Clin. Invest. 52:2745-2756.

39. Rosenthal, A. S. 1980. Regulation of the immune response: role of the macrophage. N. Engl. J. Med. 303:1153-1156.

40. Ringler, D. J., M. S. Wyand, D. G. Walsh, J. J. MacKey, L. V. Chalifoux, M. Popovic, A. A. Minassian, P. K. Sehgal, M. D. Daniel, R. C. Desrosiers, et al 1989. Cellular localization of simian immunodeficiency virus in lymphoid tissues. I. Immunohistochemistry and electron microscopy. Am. J. Pathol. 134:373-383

41. Ringler, D. J., W. W. Hancock, N. W. King, N. L. Letvin, M. D. Daniel, R. C. Desrosiers, and G. F. Murphy. 1987. Immunophenotypic characterization of the cutaneous exanthem of SIV-infected rhesus monkeys: apposition of degenerative Langerhans cells and cytotoxic lymphocytes during the development of acquired immunodeficiency syndrome. Am. J. Pathol. 126:199-207.

42. Ringler, D. J., W. W. Hancock, N. W. King, and G. F. Murphy. 1987. Characterization of nonhuman primate epidermal and dermal dendritic cells with monoclonal antibodies: a study of Langerhans cells and indeterminate cells in the rhesus monkey. Lab. Invest. 56:313-320.

43. Yoshimura, T., K. Matsushima, S. Tanaka, E. A. Robinson, E. Appella, J. J. Oppenheim, and E. J. Leonard. 1987. Purification of a human monocyte-derived neutrophil chemotactic factor that has peptide sequence similarity to other host defense cytokines. Proc. Natl. Acad. Sci. USA. 84:9233-9237.

44. Picker, L. J., T. K. Kishimoto, C. W. Smith, R. A. Warnock, and E. C. Butcher. 1991. ELAM-1 is an adhesion molecule for skin-homing T cells. Nature (Lond.). 349:796-799.

45. Shimizu, Y., W. Newman, T. V. Gopal, K. J. Horgan, N. Graber, L. D. Beall, G. A. van Seventer, and S. Shaw. 1991. Four molecular pathways of T cell adhesion to endothelial cells: roles of LFA-1, VCAM-1, and ELAM-1 and changes in pathway hierarchy under different activation conditions. J. Cell Biol. 113:1203-1212.

46. van Kooyk, Y., E. van de Wiel-van Kemenade, P. Weder, R. J. F. Huijbens, and C. G. Figdor. 1993. Lymphocyte function-associated antigen 1 domi- 
nates very late antigen 4 in binding of activated T cells to endothelium. J. Exp. Med. 177:185-190.

47. Lawrence, M. B. and T. A. Springer. 1991. Leukocytes roll on a selectin at physiologic flow rates: distinction from and prerequisite for adhesion through integrins. Cell. 65:859-873.

48. Rice, G. E., J. M. Munro, and M. P. Bevilacqua. 1990. Inducible cell adhesion molecule 110 (INCAM-110) is an endothelial receptor for lymphocytes: a CD11/CD18-independent adhesion mechanism. J. Exp. Med. 171:1369-1374.

49. Bevilacqua, M. P., J. S. Pober, D. L. Mendrick, R. S. Cotran, and M. A. Gimbrone, Jr. 1987. Identification of an inducible endothelial-leukocyte adhesion molecule. Proc. Natl. Acad. Sci. USA. 84:9238-9242.

50. Bevilacqua, M. P., S. Stengelin, M. A. Gimbrone, Jr., and B. Seed. 1989 Endothelial leukocyte adhesion molecule $1:$ an inducible receptor for neutrophils related to complement regulatory proteins and lectins. Science (Wash. DC). 243:1160-1165

51. Spertini, O., F. W. Luscinskas, G. S. Kansas, J. M. Munro, J. D. Griffin M. A. Gimbrone, Jr., and T. F. Tedder. 1991. Leukocyte adhesion molecule(LAM-1, L-selectin) interacts with an inducible endothelial cell ligand to support leukocyte adhesion. J. Immunol. 147:2565-2573.

52. Carlos, T. M., B. R. Schwartz, N. L. Kovach, E. Yee, M. Rosso, L. Osborn, G. Chi-Rosso, B. Newman, R. Lobb, and J. M. Harlan. 1990. Vascular cell adhesion molecule-1 mediates lymphocyte adherence to cytokine-activated cultured human endothelial cells. Blood. 76:965-970.

53. Carlos, T., N. Kovach, B. Schwartz, M. Rosa, B. Newman, E. Wayner, C. Benjamin, L. Osborn, R. Lobb, and J. Harlan. 1991. Human monocytes bind to two cytokine-induced adhesive ligands on cultured human endothelial cells: endothelial-leukocyte adhesion molecule-1 and vascular cell adhesion molecule-1. Blood. 77:2266-2271.

54. Bochner, B. S., F. W. Luscinskas, M. A. Gimbrone, Jr., W. Newman, S. A Sterbinsky, C. P. Derse-Anthony, D. Klunk, and R. P. Schleimer. 1991. Adhesion of human basophils, eosinophils, and neutrophils to interleukin 1-activated human vascular endothelial cells: contributions of endothelial cell adhesion molecules. J. Exp. Med. 173:1553-1556.

55. Westlin, W. F., and M. A. Gimbrone, Jr. 1993. Neutrophil-mediated damage to human vascular endothelium. Am. J. Pathol. 142:117-128.

56. Gundel, R. H., C. D. Wegner, C. A. Torcellini, C. C. Clarke, N. Haynes, J. Rothlein, C. W. Smith, and L. G. Letts. 1991. Endothelial leukocyte adhesion molecule-1 mediates antigen-induced acute airway inflammation and late-phase airway obstruction in monkeys. J. Clin. Invest. 88:1407-1411.

57. Podolsky, D. K., R. Lobb, N. King, C. D. Benjamin, B. Pepinsky, P. Sehgal, and M. deBeaumont. 1993. Attenuation of colitis in the cotton-top tamarin by anti- $\alpha 4$ integrin monoclonal antibody. J. Clin. Invest. 92:372-380. 